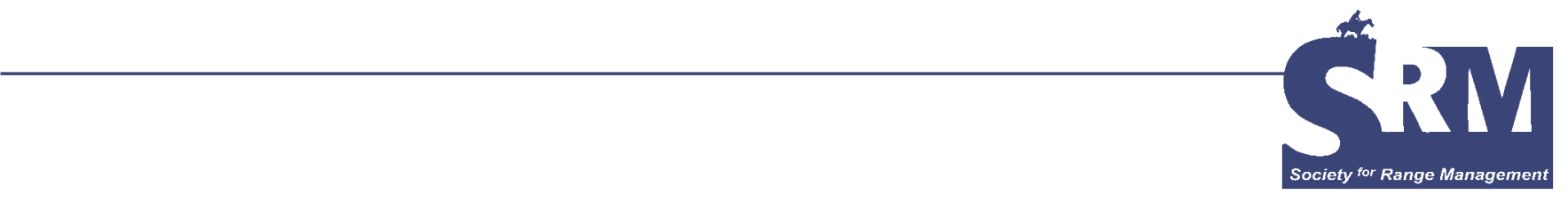

\title{
Full-Text Online Access to Society for Range Management Journals
}

\section{By Jeanne L. Pfander, Yan Han, Lindsay Wyatt, and Marianne Stowell Bracke}

\section{Introduction}

I

$\mathrm{n}$ the past 10 years, full-text journal content on the World-Wide Web (WWW) has exploded. In 1996, the Directory of Electronic Journals, Newsletters and Academic - Discussion Lists, published by the Association of Research Libraries, listed 1,689 journal and newsletter entries, $90 \%$ of which included a Web address. ${ }^{1}$ By late 2003, approximately 14,600 online and active and academic/scholarly or refereed journals were available. ${ }^{2}$ Customer demand, especially on university campuses, is high. Readers appreciate the convenience of being able to access full-text online copies of articles 24/7 from the comfort of their offices, labs, dorm rooms, or homes. The expectation that you can (or should be able to) find everything on the Web has become ubiquitous. Librarians have been eager to satisfy customer needs for more full-text online content. Even so, there have been issues of pricing and also quality control in online journals, especially regarding information-rich images and so on in scientific journals. In addition, librarians have had concerns regarding the licenses for online journals, especially pertaining to perpetual access to content paid for in the event a subscription is canceled.

Publishers have been feeling their way in this new arena, unsure of the economic model to follow. Contributing to the dynamic state of affairs has been the open access movement. Many librarians and other faculty or researchers in academia and government have argued for free access to journal articles, especially when the research has been funded by taxpayers. (For more information on the open access movement, see the Wikipedia article "Open access" at http://en.wikipedia. org/w/index.php?title=Open\%20access\&oldid=29738975.)

The University of Arizona Library, working with the Society for Range Management, was a pioneer in the mid- 1990s in providing full-text Web-based open access to the early volumes of the Journal of Range Management (JRM). More recently, volumes 1-20 (1979-1998) of the journal Rangelands have been digitized by the University of Arizona Library. This paper describes the history of both digitization projects, their current status, and plans for the future.

\section{AgNIC Rangelands and the University of Arizona}

The University of Arizona (UA) has been a part of the Agriculture Network Information Center (AgNIC; http://www.agnic.org), centered at the National Agricultural Library, since its inception in $1995 .^{3}$ The UA chose to develop a Web-based information center for rangelands since they are crucial to Arizona but are also of global importance and therefore appropriate as a topic for AgNIC. The mission of the Arizona AgNIC project is to provide electronic access to the full scope of information in the field of rangelands and rangeland management to people everywhere and of all knowledge levels by collecting, creating, evaluating, and organizing relevant resources. The Arizona Rangelands site resides at http://ag.arizona.edu/agnic/az/index.html.

AgNIC Rangelands has continued to evolve. In 2002, the Arizona AgNIC team brought together cooperative extension agents and librarians from land grant institutions from 12 western U.S. states to expand the AgNIC Rangelands project. $^{4}$ This initiative, which has since grown to 21 participating institutions in 19 states, is now known as the Western Rangelands Partnership, and a central Web site has been created named Rangelands West (http://rangelandswest.org). From this site, links lead to state pages that address local needs and issues. 


\section{Digitizing JRM}

The Arizona AgNIC Rangelands team has a long history of pursuing opportunities to create or support the creation of online access to more content. In 1995, 2 events were taking place that came together serendipitously. SRM contacted the National Agricultural Library (NAL) about the possibility of digitizing back files of $J R M$. At the same time, the Arizona AgNIC project was just getting off the ground and was beginning to add content to the site. NAL brought the 2 groups together. The UA entered into an agreement to digitize the back files of $J R M$, and a memorandum of understanding between the UA, SRM, and NAL was drafted. NAL provided funds for the digitization work. SRM agreed to provide the print copies of the back issues from 1948-1994 for the Arizona rangelands project team to scan. The process of scanning, plus creating the Web architecture for delivering the initial online back files, was done in house at the UA Library and was completed in 1999. ${ }^{5}$ Two years later, the project team added volumes for 1995-1998 that were provided in digital form by Cornell University as a by-product of TEEAL (The Essential Electronic Agricultural Library; http://teeal.cornell.edu/). More recently, additional volumes for 1999-2001 have been provided by SRM in digital form. SRM will deliver additional volumes as the rolling window agreed on in the memorandum of understanding continues to move. The JRM archive site (http://jrm.library.arizona.edu/) includes the full text for all issues of the journal from 1948 to 2001. Issues can be accessed by browsing through an index by date. For the years 1983-2001, the archives can also be searched by general key word, author, or title.

\section{Digitizing Rangelands}

For several years, the Arizona Rangelands AgNIC group had been discussing the desirability of working with SRM to make the back files of the journal Rangelands available online. In April 2004, NAL announced that funding for small cooperative agreements was being made available to AgNIC partners. The objective of the cooperative agreement was to support an effort between participating institutions and NAL to build full-text content that would deliver information to Internet users through the $\mathrm{AgNIC}$ (M. Gardner, unpublished e-mail communication, 2004). The authors of this paper submitted a proposal to digitize volumes 1-20, 1979-1998, of Rangelands. The proposal was funded by NAL.

An agreement similar to that developed for the earlier $J R M$ digitization project was reached between the UA and SRM for the digitization of Rangelands. SRM agreed to provide 1) print copies of volumes and 2) rights to unlimited, free-of-charge use of the digitized data consistent with Title 17 of the U.S. Code on Copyright. The UA Library agreed to 1) scan the printed material and create digitized TIFF and PDF files, 2) make this information available over their Web site, 3) provide SRM with 2 free copies of the TIFF and PDF files and make additional copies at cost if requested, and 4) make the Rangelands articles from the UA Library

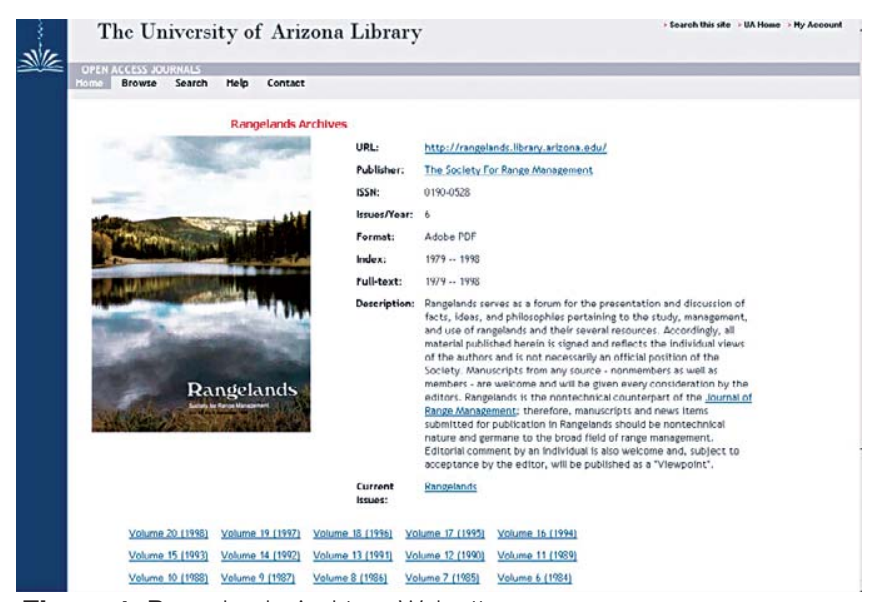

Figure 1. Rangelands Archives Web site.

Web site directly accessible from other Web sites that emphasize rangeland information, particularly the SRM home page site (http://www.rangelands.org/).

The UA Library outsourced the scanning work. A vendor was selected and a contract signed regarding the requirements, costs, and timing for completion of the work. When the contract was in place, SRM shipped the Rangelands volumes to the vendor for digitization.

The UA Library project team designed the Rangelands Archives Web site with the objective of providing an optimum customer experience. With a few clicks, customers can easily browse, quickly locate, and access full-text articles.

\section{SRM and Online Access to Recent/ Current Volumes}

A related development has been the partnership between the SRM and Alliance Communications Group (ACG). Over the past few years, the Rangelands and Journal of Range Management Steering Committees have worked with the editors in chief, associate editors, and ACG staff to redesign the 2 SRM journals. ${ }^{6} J R M$ has been renamed Rangeland Ecology \& Management (REM). Current issues and recent volumes of both journals are now available full-text online.

SRM members have access to Rangelands (print and online) through their basic membership status. For an additional $\$ 30.00$ (as of January 1, 2006), members can subscribe to $R E M$ (print and online).

Both SRM journals are also available to institutions on a subscription basis through BioOne (http://www.bioone.org), beginning with the volumes for 2004 and continuing to the present.

\section{Next Steps for the Archives}

SRM will continue to provide the full-text journal articles in electronic form to the UA Library for both the Rangelands and $J R M / R E M$ Archives sites. This will be, as before, on a rolling window basis, with content available via the UA open access archives 2-3 years after being published. 
The UA Library has several enhancements in the works for the Archives. We are working to fill in gaps in indexing for articles in both Rangelands and JRM. Indexing records allow users to search the Archives by author or keyword. With permission from the National Agriculture Library, the UA Library project team had downloaded AGRICOLA database records for both SRM journal articles. It was determined, however, that 100 articles in some of the issues of early volumes (1979, 1980, and 1981) of Rangelands do not have records. The project team is currently indexing these articles and expects to complete and load those records before March 2006. In addition, pre-1983 JRM articles were not indexed by AGRICOLA, and the UA Library will be adding indexing to allow key word and author searching for those volumes as well.

Sustainability and maintenance of the Archives is an ongoing concern. The UA Library will continue to evaluate the appropriateness of changing technologies and work to create a consistent and user-friendly Web interface and digital infrastructure to host the $J R M / R E M$ and Rangelands Archives.

\section{Conclusion}

The UA Library and SRM have a productive working relationship. By making the valuable intellectual content of the SRM journal publications available online, the creativity and productivity of researchers, students, resource managers, and decision makers concerned with rangelands will be enhanced.
Authors are Associate Librarian, Science-Engineering Team, University of Arizona Library,Tucson, AZ, pfanderj@u.library. arizona.edu (Pfander); Assistant Librarian, Digital Libraries and Information Systems Team, University of Arizona Library, Tucson, AZ (Han); Graduate Student, School of Information Resources and Library Science, University of Arizona, Tucson, AZ (Wyatt); and Assistant Librarian, Science-Engineering Team, University of Arizona Library, Tucson, AZ (Bracke).

\section{References}

1. Mogge, D. 1999. Seven years of tracking electronic publishing: the ARL Directory of Electronic Journals, Newsletters and Academic Discussion Lists. Library Hi Tech 17:17-25.

2. TenOPIR, C. 2004. Online scholarly journals: how many? Library Journal 129:32.

3. Gardner, M., J. Gilbertson, and B. S. Hutchinson. 2002. Partnering for improved access to agricultural information: the agriculture network information center (AgNIC) initiative. ARL: a bi-monthly newsletter of research library issues and actions 223:5-10.

4. Hutchinson, B. S., D. Jones, And G. B. Ruyle. 2003. Building a collaborative AgNIC site as an outreach model: rangelands of the western U.S. Reference Librarian 82:125-140.

5. Hutchinson, B. S., And G. B. RuYle. 2000. Wired without the barbs: using the internet for rangeland information. Rangelands 22:19-22.

6. Kothmann, M. 2005. Exciting changes in SRM publications. Rangelands 27:2. 